\section{Code of conduct for geoengineering}

Geoengineering is central to scenarios that limit global warming to $2^{\circ} \mathrm{C}$ - for example, by removing carbon dioxide from the atmosphere or increasing the planet's albedo (see Nature 527, 436-438; 2015). However, the environmental and social implications of such technology are holding back research. Developing an international code of conduct could resolve this conundrum by ensuring that geoengineering proposals are subject to societal scrutiny and oversight.

The code would provide flexible governance for a wide range of projects, along with general principles and procedures to guide responsible research and to inform regulatory processes for technologies as they develop (see go.nature.com/2ceitmv).

As well as encouraging early cooperation and coordination of research, equity and sustainable development in the spirit of the 2015 Paris climate agreement, the code should promote precaution, risk assessment, public participation and transparency.

Anna-Maria Hubert University of Calgary, Canada.

Tim Kruger, Steve Rayner University of Oxford, UK. annamaria.hubert@ucalgary.ca

\section{Do microplastics spill on to farm soils?}

Large quantities of microplastic particles from cosmetics, clothing and industrial processes could be ending up on agricultural land that is fertilized with urban sewage sludge. This calls for urgent investigation if we are to safeguard food production and reuse wastewater products.

Unlike microplastics that pollute the oceans, little is known about the particles' prevalence and potential effects in terrestrial and freshwater environments.
Because they are retained in sewage and domestic waste water after treatment in municipal plants (S. A. Carr et al. Water Res. 91, 174-182; 2016), they could be contaminating agricultural soils - with unknown consequences for farm ecosystems and food security.

We estimate from emissions data (see, for example, go.nature. com/2ce0z6l) that 63,000 430,000 and 44,000-300,000 tonnes of microplastics could be being added annually to farmlands in Europe and North America, respectively.

This figure exceeds the estimated global burden of microplastics in oceanic surface waters of 93,000-236,000 tonnes (E. van Sebille et al. Environ. Res. Lett. 10, 124006; 2015).

Luca Nizzetto, Sindre Langaas Norwegian Institute for Water Research, Oslo, Norway. Martyn Futter Swedish University of Agricultural Sciences, Uppsala, Sweden. luca.nizzetto@niva.no

\section{Species loss: lack of data leaves a gap}

Understanding the pressures that lead to a high risk of species extinction is crucial for stemming biodiversity loss (see S. L. Maxwell et al. Nature 536, 143-145; 2016). Yet the large number of species that remain classified as data deficient can introduce considerable uncertainty in identifying these drivers.

Data-deficient species represent 1 in 6 species on the IUCN Red List, or some 13,465 species. Uncertainties about drivers of extinction depend on the proportion of such species within a group (S. H. M. Butchart and J. P. Bird Biol. Conserv. 143, 239-247; 2010). In birds, uncertainty is low because just $0.58 \%$ of species are data deficient; $24 \%$ of amphibians and $49 \%$ of freshwater crabs are data deficient, so uncertainty in these groups is likely to be high.
Data-deficient species tend to have limited geographical ranges, be small in size and occupy highly specific, remote habitats (L. M. Bland et al. Conserv. Biol. 29, 250-259; 2015). They are unlikely to be threatened by hunting, but could be susceptible to deforestation and climate change, for example.

Addressing the problem of data deficiency is fundamental to diagnosing the causes of high extinction risk, and therefore to planning conservation strategies. Lucie Bland University of Melbourne, Victoria, Australia. Ben Collen University College London, UK.

l.bland@unimelb.edu.au

\section{Africa-India health- science partnerships}

Africa and India have common problems of communicable and non-communicable diseases, high maternal and child mortality, and weak healthdelivery systems. Together with other funders, the Wellcome Trust is supporting capacitybuilding and innovation in health research in both regions, through the Alliance for Accelerating Excellence in Science in Africa (AESA) and the India Alliance.

A flourishing trade in low-cost Indian drugs is transforming health care in Africa. However, India and many African countries spend less than $1 \%$ of their total gross domestic product on science and technology, and have abysmally few researchers - even though Africa and India together contain almost one-third of the world's population and share half of its disease burden.

This month's India-Africa Health Sciences meeting discussed how best to utilize the US\$100-million Development Fund and \$10-million Health Fund that the Indian government pledged to Africa last year. Common goals, knowledge generation and innovation are to be the pillars of

this partnership.

We invite other international funders and governments to join in to scale up local and inter-regional partnerships. Many African governments are now prepared to complement international and bilateral investments in science in Africa.

Shahid Jameel The Wellcome Trust/DBT India Alliance, New Delhi, India.

Thomas Kariuki AESA, African Academy of Sciences, Nairobi, Kenya.

Simon Kay Wellcome Trust, London, UK.

shahid.jameel@wellcomedbt.org Competing financial interests declared; see go.nature.com/2cbjem4

\title{
Lure gamers into citizen science
}

Ecologists who are interested in using Pokémon Go to find new species (see Nature 535, 323-324 (2016) and F. de Oliveira Roque Nature 537, 34; 2016) could also adopt the gameplay concept to set up wildlife-monitoring schemes that are fun for the public.

Laboratories cannot afford to hire millions of field assistants worldwide. A virtual platform could provide such a facility for free. Huge amounts of data can be gathered by video gamers, with the potential to engage with environmental issues on a much bigger scale.

These citizen scientists would also acquire a heightened awareness of natural history, taxonomy and contemporary environmental concerns.

Rassim Khelifa University of Zurich, Switzerland. rassim.khelifa@ieu.uzh.ch

CONTRIBUTIONS

Correspondence may be sent to correspondence@ nature.com after consulting the guidelines at http:// go.nature.com/cmchno 